\section{俩 Heighten Science \\ P U B L I C I T I O N S Corporation ISSN \\ 2639-3182}

\title{
Diagnosis of Asthma in Childhood Age
}

\author{
Ibrahim A Ali ${ }^{1 *}$, Elia Adil Nabih ${ }^{2}$ and Ahmed MS Eltohami ${ }^{2}$ \\ ${ }^{1}$ Faculty of Medicine, The National Ribat University, Sudan \\ ${ }^{2}$ Faculty of Medicine, University of Khartoum, Sudan
}

*Address for Correspondence: Dr. Ibrahim A Ali, Department of Physiology, Faculty of Medicine,

The National Ribat University, Sudan, Tel:

249912377276; Email: hemamedicine@gmail.com

Submitted: 27 August 2018

Approved: 12 September 2018

Published: 13 September 2018

Copyright: (C2018 Ali IA, et al. This is an open access article distributed under the Creative Commons Attribution License, which permits unrestricted use, distribution, and reproduction in any medium, provided the original work is properly cited

\section{Abstract}

Background: Asthma is the most common chronic respiratory disorder in childhood Asthmatic attacks are described and classified according to the type of wheezing to Non -atopic and Atopic asthma (IgE mediated wheezing). The aim of this review is to determine the onset of clinical diagnosis in relation to clinical presentation of asthma in children and obstacles related to delay of Asthma diagnosis.

Methods: This review highlights the results of studies done regarding clinical diagnosis in relation to clinical presentation and of asthma in children. An extensive search has been conducted for researches about asthma in children. This search based on the publications posted on the National Center for Biotechnology Information PubMed or by Google Scholar. Key words used for the research: Asthma, clinical diagnosis, children.

Results and Conclusion: Diagnosing asthma in young children is difficult because children often cough and wheeze with colds and chest infections, but this is not necessarily asthma. Miss diagnosis of asthma in children occurs when physicians diagnose patients with asthma from the clinical diagnosis in the first attack without excluding other asthma mimickers which can be any other respiratory problem. There is over-diagnosis of asthma due to the symptoms which mimic other respiratory infections. First episodes of cough, runny nose and fever that happen in cold/ flu season- fall/winter/early spring is likely not asthma. If the child has several more episodes of wheeze and cough, it is likely to be asthma. Since there is no diagnostic test available for children younger than 6 years of age, making a diagnosis in this age group is more difficult than in older children. Over the age of about 6 years it is possible for a child to have a spirometer test.

\section{Introduction}

Asthma is the most common chronic respiratory disorder in childhood. Asthma is a disorder that causes the airways of the lungs to swell and narrow, leading to wheezing, shortness of breath, chest tightness, and coughing [1].

Asthmatic attacks are described and classified according to the type of wheezing to: Non -atopic, Atopic asthma (IgE mediated wheezing).

Non- atopic wheezing: have normal lung function early in life, but a lower respiratory illness due to a viral infection usually RSV led to increased wheezing during the first ten years of life. This type seems to cause less severe persistent wheezing, and symptoms improve during adolescence.

Atopic asthma: lung function is normal at birth, but recurrent wheeze develops with allergic sensitization, with increased blood IgE and positive skin prick tests to common allergens. Atopic wheezes have persistence of symptoms and have decreased lung function later in childhood. Risk factors for the development of atopic wheeze (asthma) are family history of asthma or allergy and a history of eczema, while exposure to tobacco smoke or prematurity are not risk factors.

Pathophysiology of Asthma results in chronic inflammation of the airways involving eosinophils, lymphocytes, mast cells and neutrophils. The inflammation causes widespread but variable airflow obstruction, with bronchoconstriction, mucosal 
edema and excessive mucus production. The airflow obstruction is often reversible, either spontaneously or with treatment, and is associated with an increase in airway responsiveness to variety of stimuli such as exercise, cold air or allergen exposure.

Atopy and Allergy: atopy is an inherited predisposition to sensitization to allergens, and is present in up to $40 \%$ of children, most of whom are asymptomatic. Atopic children are at increased risk of allergic disease [1].

Diagnosis of Asthma is usually made on a history of recurrent wheeze, with exacerbation usually precipitated by viral respiratory infection [1].

Recording of the peak expiratory flow rate (PEFR) may be useful most children over 5 years of age can use a peak flow meter. Asthma results in increased variability in peak flow, both diurnal variability (morning PEFR usually lower than evening PEFR) and day-to-day variability. There may also be bronchodilator responsiveness, where PEFR will increase by more than $10-15 \%$ after inhaling a bronchodilator. Often response to treatment is the most helpful investigation [1].

In most children, the symptoms of asthma are readily controlled, but it is an important cause of school absenteeism, restricted activity and anxiety for the child and family. The problem statement that highlighted in this review article is that most children have diagnosed with asthma after several attacks instead that should be diagnosed from first time to take prober management of asthma or can be diagnosed early before the criteria of diagnosis was established. Factor which lead to this problem is that the symptoms of asthma and other respiratory problems mimic each other's.

Asthma is one of the commonest chronic illnesses in children. There have been important advances in the understanding of prevalence, pathophysiology, monitoring and treatment of asthma in recent years. However, there is only little information on the natural history of asthma [1-5], which is one of the major obstacles to the development of preventive strategies for asthma. It is important to diagnose Asthma at an early stage as early treatment may improve the prognosis in the long term. However, many patients do not present at an early stage of the condition, so the physician may have difficulty with the diagnosis. Under diagnosis and consequent under treatment might be important in the increased morbidity and mortality of asthma.

Miss diagnosis of asthma in children is that when physicians diagnose patients with asthma from the clinical diagnosis in the first attack without excluding other asthma mimickers which can be any other respiratory problem.

\section{Definitions}

The following terms and definitions were applied to this Review:

Age of onset of symptoms: the age at which children experience symptoms for first time.

Age of diagnosis: Age at which patients confirmed as asthmatic patients.

Aggravating factors: Factors that lead to asthmatic attacks.

The literature review was done using the following subheadings:

- The definition of asthma.

- The age of onset of symptoms.

- Asthma and Family history

- Diagnosis of asthma in children 


\section{The definition of asthma}

Asthma is an airway disease that can be classified physiologically as a variable and partially reversible obstruction to air flow, and pathologically with overdevelopedmucus glands, airway thickening due to scarring and inflammation, and bronchoconstriction, the narrowing of the airways in the lungs due to the tightening of surrounding smooth muscle. Bronchial inflammation also causes narrowing due to edema and swelling caused by an immune response to allergens.

\section{The age of onset of symptoms}

The result of epidemiological study is heavily influenced by the definition of asthma. The diagnosis may be based on the subject's self-reporting of symptoms [6], or by stringent clinical criteria as used by Yunginger [1].

Morgan's [2] study. showed that $79 \%$ of children with persistent asthma at 16 years old had their onset of asthma before pre-school age, with asthma had symptoms before 6 year of age. In contrast to Yunginger's [1], which showed that the median age of onset of asthma was 3 year for males and 8 year for female children.

\section{Asthma and family history}

There was a strong family history of asthma (49.6\%) and allergic diseases (75.7\%) in asthmatic children. ${ }^{(2)}$ It supports the notion that there is a strong genetic component on the development of asthma.

Lowe et al. [7] suggested significant interaction between maternal asthma and lung function in early childhood; Kurukulaaratchy et al. [8] showed that allergic comorbidity and maternal asthma emerged as strong factors for persistent wheezing states. Recent studies $[9,10]$ suggested that the damage to lung tissues in asthma also began early in life. Longitudinal population-based study from Sear et al. [9] showed that derangement in lung function was already present by early school ages in whom persistent asthma would ultimately develop.

Since asthma begins early in childhood, and the damage also starts in early life, it is reasonable to target intervention in early life for the prevention of asthma. Efforts have been made to manipulate the environmental risk factors like house dust mite allergen avoidance [11,12], pet exposure [13,14] and dietary avoidance [15-17], in early life for primary prevention of asthma, but unfortunately the results so far have been conflicting. Understanding the natural history of asthma will shed light on the approaches for the prevention of asthma.

\section{Diagnosis of asthma in children}

Diagnosing asthma in young children is difficult because children often cough and wheeze with colds and chest infections, but this is not necessarily asthma. Young children have very small, narrow airways and on average have a $6-8$ colds per year, usually between September and March. Some physicians are reluctant to give a diagnosis of asthma to young infants as other conditions can be responsible for the asthma like symptoms. Children and toddlers can wheeze when they have viral infections. Bronchiolitis is another very common cause of wheeze in children. First episodes of cough, runny nose and fever that happen in cold/flu season-fall/winter/ early spring is likely not asthma. If the child has several more episodes of wheeze and cough, it is likely to be asthma. The common cold triggers $90 \%$ of asthma attacks in children, compared to $40 \%$ in adults. Since there is no diagnostic test available for children younger than 6 years of age, making a diagnosis in this age group is more difficult than in older children. Over the age of about 6 years it is possible for a child to have a spirometer test. This is a simple test that measures a child's airflow through the large and small airways. Results reveal if the child's airflow can be improved 
with medication. Reversibility of airway obstruction is a key feature of asthma. If administering a bronchodilator reverses airway narrowing significantly, the diagnosis is probably asthma.

Data show that the diagnosis constitutes a first necessary step in getting a treatment. In comorbidities, such as eczema, rhinitis, and allergic sensitization increased the likelihood of treatment, as asthma severity did. The treatment is related to a greater severity, more frequent asthma attacks, more frequent awakenings due to wheezing, and a higher number of school days missed thus confirming previous data.

The links between asthma and other allergies are already known but have rarely been connected with the under-diagnosis and under-treatment of asthma. Allergic rhinitis and eczema are associated with more severe asthma. In addition, allergic rhinitis is also associated with a sub-diagnosis and under-treatment. We also observed that the perception and the assumption of disease were lower in the undiagnosed asthmatic population. When we looked at the asthma medication in people who were not diagnosed, we found that there was a significant decrease in appropriate treatments. In previous study was also show that children with symptomatic asthma but no diagnosis had less well-controlled asthma than children with diagnosed asthma, since their quality of life determined by nocturnal awakenings and truancy was not optimal. In previous studies, it was shown that the health implications could be significant in asthmatics without a proper diagnosis, because they were less treated than diagnosed asthmatics: they missed more days of school because of wheezing, they limited their physical activity, and their sleep was more disrupted [18].

Nabi et al., study showed that $39 \%$ of asthmatic children presented at $<1$ year, $22 \%$ presented at $1-2$ years and $39 \%$ presented at $>2$ years. The common age of diagnosis is $1-2$ years $34 \%,<1$ year $32 \%$ which may suggest that there is overdiagnosis because children often cough and wheeze with colds and chest infections but this is not necessarily asthma. Young children have very small, narrow airways and on average have a $6-8$ colds per year, usually between September and March. Some physicians are reluctant to give a diagnosis of asthma to young infants as other conditions can be responsible for the asthma like symptoms. Children and toddlers can wheeze when they have viral infections. Bronchiolitis is another very common cause of wheeze in children. First episodes of cough, runny nose and fever that happen in cold/flu season- fall/winter/early spring is likely not asthma. The strong association between, family and personal history, and asthma added to clinical examination, are useful in differentiating between asthma and other acute respiratory conditions [19].

\section{Recommendations}

To improve the performance of practitioners regarding the diagnosis of asthma, good history and clinical examination as follow:

- Personal and family history of atopy is of paramount important.

- Proper clinical examination must be conducted.

- Proper treatment for asthma is required.

- $\quad$ Parents must be counseled.

- Health education to mother about the common aggravating factors to prevent her children.

\section{References}

1. Yunginger JW, Reed CE, O'Connell EJ, Melton LJ 3rd, O'Fallon WM, et al. A community-based study of the epidemiology of asthma. Incidence rates, 1964-1983. Am Rev Respir Dis. 1992;146: 888-894. Ref.: https://goo.gl/or9xTB 
2. Morgan WJ1, Stern DA, Sherrill DL, Guerra S, Holberg CJ, et al. Outcome of asthma and wheezing in the first 6 years of life: follow-up through adolescence. Am J Respir Crit Care Med. 2005; 172: 12531258. Ref.: https://goo.gl/GSNmHW

3. Hahn DL. Does most asthma really begin during the preschool years? Am J Respir Crit Care Med. 2006; 173: 575-576. Ref.: https://goo.gl/RrV859

4. Dodge RR, Burrows B. The prevalence and incidence of asthma and asthma-like symptoms in a general population sample. Am Rev Respir Dis. 1980; 122: 567-575. Ref.: https://goo.gl/bsmXz4

5. Blair H. Natural history of childhood asthma. 20-year follow up. Arch Dis Child. 1977; 52: 613-619. Ref.: https://goo.gl/E1qpv3

6. Worldwide variations in the prevalence of asthma symptoms: the International Study of Asthma and Allergies in Childhood (ISAAC). Eur Respir J. 1998; 12: 315-335. Ref.: https://goo.gl/QHyH5B

7. Lowe L, Murray CS, Custovic A, Simpson BM, Kissen PM, et al. Specific airway resistance in 3-yearold children: a prospective cohort study. Lancet. 2002; 359: 1904-1908. Ref.: https://goo.gl/5Lxws9

8. Kurukulaaratchy RJ, Matthews S, Arshad SH. Does environment mediate earlier onset of the persistent childhood asthma phenotype? Pediatrics. 2004; 113: 345-350. Ref.: https://goo.gl/3ZdJ33

9. Sears MR, Greene JM, Willan AR, Wiecek EM, Taylor DR, et al. A longitudinal, population-based, cohort study of childhood asthma followed to adulthood. N Engl J Med. 2003; 349: 1414-1422. Ref.: https://goo.gl/6L4wBS

10. Childhood Asthma Management Program Research Group, Szefler S, Weiss S, Tonascia J, Adkinson $\mathrm{NF}$, et al. Long-term effects of budesonide or nedocromil in children with asthma.N Engl J Med. 2000; 343: 1054-1063. Ref.: https://goo.gl/yqHvTb

11. Horak F Jr, Matthews S, Ihorst G, Arshad SH, Frischer T, et al. Effect of mite impermeable mattress encasings and an educational package on the development of allergies in a multinational randomized, controlled birth-cohort study -- 24 months results of the Study of Prevention of Allergy in Children in Europe. Clin Exp Allergy 2004; 34: 1220-1225. Ref.: https://goo.gl/aMNdMd

12. Brunekreef B, Smit J, de Jongste J, Neijens $H$, Gerritsen J, et al. The prevention and incidence of asthma and mite allergy (PIAMA) birth cohort study: design and first results. Pediatr Allergy Immunol 2002;13 Suppl 15: 55-60. Ref.: https://goo.gl/RZgoxg

13. Fasce L, Tosca MA, Silvestri M, Olcese R, Pistorio A, et al. "Early" cat ownership and the risk of sensitization and allergic rhinitis in Ligurian children with respiratory symptoms. Ann Allergy Asthma Immunol 2005; 94: 561-565. Ref.: https://goo.gl/bQ9enw

14. Lau S, Illi S, Platts-Mills TA, Riposo D, Nickel R, et al. Longitudinal study on the relationship between cat allergen and endotoxin exposure sensitization, cat-specific IgG and development of asthma in childhood--report of the German Multicentre Allergy Study (MAS 90). Allergy 2005; 60: 766-773. Ref.: https://goo.gl/DEgqTk

15. Kramer MS, Kakuma R. Maternal dietary antigen avoidance during pregnancy or lactation, or both, for preventing or treating atopic disease in the child. Cochrane Database Syst Rev. 2006; 3: CD000133. Ref.: https://goo.gl/zwbHHA

16. Baker SS, Cochran WJ, Greer FR, Heyman MB, Jacobson MF, et al. Hypoallergenic infant formulas. Pediatrics 2000; 106: 346-349. Ref.: https://goo.gl/bm5sZh

17. Høst A, Koletzko B, Dreborg S, Muraro A, Wahn U, et al. Dietary products used in infants for treatment and prevention of food allergy. Joint Statement of the European Society for Paediatric Allergology and Clinical Immunology (ESPACl) Committee on Hypoallergenic Formulas and the European Society for Paediatric Gastroenterology, Hepatology and Nutrition (ESPGHAN) Committee on Nutrition. Arch Dis Child. 1999; 81: 80-84. Ref.: https://goo.gl/FqHB4G

18. Ruokonen $M$, Kaila $M$, Haataja $R$, Korppi $M$, Paassilta $M$, Allergic rhinitis in school-aged children with asthma - still under-diagnosed and undertreated? A retrospective study in a children's hospital. Pediatr Allergy Immunol. 2010; 1Pt 2: 149-154. Ref.: https://goo.gl/nKx2mr

19. Nabih EA, Ibrahim A Al. Clinical Diagnosis of Asthma in Children. International Journal of Science and Research (IJSR). 2018; 7: 1648-1654. Ref.: https://goo.gl/GuADS1 